\title{
A Novelty for the Definition of Virtuous Economic Framework of the Italian Motorway Traffic Management: MPCA Model
}

\author{
Moreno Ferrarese \\ Department of Economics, University of Verona, Italy \\ Academic Research Center "The Hub", Verona, Italy
}

Copyright (C) 2015 Horizon Research Publishing . All rights reserved.

\begin{abstract}
The precise and reliable assignment of parameters of the economic scenery, aimed at planning of motorway traffic, can not be separated from the analysis of the parameters of motorway safety as conflicting elements in the decision-making capacity management in "crisis conditions" due to natural events or as a cause of the job scheduling road maintenance. The fundamental problem for the concessionaire of the motorways lies in the quest for the best balance between motorway safety for driver-players and the revenue from tolls paid by owners of the vehicles? In fact, in case of a crisis due to accidental events or scheduled ones as the fixed and mobile road yards, the revenue of the company is changing. This study achieves the implementation of a management model of business revenue under crisis conditions. Through repeated field surveys we have built and calibrated an economic model IT based - that offers immediate answers for the motorways' management. So, we present a new method for the economic balance of the motorway infrastructure, in the very short term.
\end{abstract}

Keyword Motorway Safety-Loss Account- Motorway Management Model

JEL Codes: R4, R15

\section{Introduction}

The chronic news have accustomed us to hear about the motorway crashes with dozens of road casualties and damages to vehicles and infrastructures: factors that engage the motorways' dealership companies in continually reviewing their safety plans and the placement of fixed and mobile road yards, in order to ensure the high speed of vehicles in relation to the legal management's conditions for the purpose of which the motorways and the fast flowing roads are built - and the safety of the vehicles' drivers in the different sections of motorways.

Under some conditions, particularly the critical ones, due to seasonality, frequency of traffic, sliding time and weather conditions, which are natural factors affecting motorway safety - together with the activation of maintenance or circulation improvement systems, given by travelling or fixed road yards (as technical factors that interfere with road's safety) - we observe disturbances to the circulation of vehicles that create motorway crashes.

In their studies, Kroes and Sheldon [1] indicate the overall frequency of motorways crashes, in the presence of congestion, almost defined as double of motorways' one, with free-flow conditions. In relation to these cases, since the increase of the capacity of the motorways is not always possible through the maintenance improvements, it is sometimes preferable to use other approaches such as the regulation of the flow that has the reduction of congestion and crash rates as primary objective (e.g. in the study of Zhou M., Sisiopiku V.P. [2]).

In the downflows, the flows of vehicles or people regulate their joint motion, given by pace or driving behavior (as it's described in Ferrari P. [3]), which induces drivers or pedestrians to adjust their velocity and their trajectories with respect to the positions and movements of other vehicles and pedestrians, through the temporal, cost, safety, comfort choices.

The dynamic assignment of flows lets to reproduce the time-varying load in each section of motorway infrastructure and, thus, makes it possible to predict the onset of congestion which is due to an excess of demand over the local road capacity (e.g. in Garavello M., Piccoli B. [4]).

Also, it offers the opportunity to evaluate both the percentage of flow coming from any particular access ramp on the overall value of the expected load at any point of the network, and when the incoming flow will be positioned at a critical point as a function of travel speed (as in Camus R., Longo G., Santorini F. [5]).

Considering that the flow patterns are different for intersections both for the different elements of the road (e.g. 
in Schultz G.G., Rilett L.R. [6]), the halts of the public transport systems (nodes/junctions), and for the elements of a path between one node and another (arcs), the realization of safety and comfort conditions is usually norm-regulated with variable modes from one mode of transport to another and, for the same transport mode, according to considered road factor (as it was explained in Toledo T., Koutsopoulos H.N., Davol A., Ben-Akiva M.E., Burghout W., Andréasson I., Johansson T., C. Lundin [7]).

The regulation system is, therefore, constituted of a set of traffic rules (e.g. motorway code, navigation code and railways' circulation trains code).

For example, in the downflow on the arcs, the road safety vehicular condition consists in keeping the safety distance of the tracker/follower on the preceding vehicle, along a trajectory intercepted by both (as in Ranjitkar P., Nakatsuji T. [8]).

In the downflow throw a vehicular node, whereby different vehicular currents share the use of a common element of the road, the decision is related to the commitment of the common buffer area (as in Schultz G.G., Rilett L.R. [9]).

Generally, with vehicular traffic on all the ground infrastructure, the mode of rout is called free density, when the implementation of the safety condition on the arcs is completely attributed to the drivers responsibility (i.e. cars, buses, as in Ferrari P. [10]); it's called controlled density, when the outdistancing between vehicles is fixed or controlled by signaling systems (e.g. cableways, funicular railways, subways, railways); it is called mixed density, when the distance between vehicles on the roadway (proper or combined) is partly self-regulated, partly under signaling (e.g. urban railways, in: Torrieri V., Gattuso D., Vitetta A. [11]).

\section{Objectives}

Since it is not possible directly to affect human behavior in conducting the vehicles on the roadway lane section without real interventions into illegality areas, it is useful to know which real interventions are possible without taking advantage in the present article in order to make planning.

We are showing that the human decision-making action of the external - under uncertainty or certainty factors - has much impact. Instead, the use of classic mobility modeling for the prevention of critical phenomena is less useful. The modeling appears, in case, to be a useful tool especially for project planning and programming of general management.

This article explores the question in relation to the search of the economic account parameters, for the managerial choices on the motorway infrastructure management in critical operating conditions, which can become the focal point of virtuous characteristic management.

This study proposes the implementation of a new management model of business revenue under "crisis conditions", which have never been developed before in spite of some efforts to explain the arguments concerning the dynamic assignment of flows reproducing the time-varying load in each section of motorway infrastructure. Such approach makes possible to predict the onset of congestion business which is due to an excess of demand over the local road capacity.

Through repeated field surveys we would build and calibrate a model that could offer immediate answers for the motorways' management, making possible to predict the onset of congestion business which is due to an excess of demand over the local road capacity.

\section{Methods of study:}

1. Space and Time of braking and stopping - fluid dynamic approach

2. Graphical analysis

3. Decision Theory, by making the driver-player to decide on the various alternative guide strategies, in the search of the pay-off line conform with its own interests

4. MPCA: use of an IT economic model to define the parameters of account

\section{Methodology: A Spatio-temporal Approach of Motorway Safety Distances (Space and Time of Braking and Stopping - fluid Dynamic Approach)}

In the presentation of the various models of traffic study, in order to highlight and define fully the negative factors such as crashes and congestion, the driver is still the referee to judge the mode of their behavior which should be more profitable in terms of safety and to implement it, then, in relation to that of other drivers. The driver behavior is essentially linked to the conditioning (as, e.g., in Gis P.G. [12]) which is mentioned above.

According to the criteria of running on sight each driver adjusts his speed in order to cope with the dangerous situation given mainly by the front-lateral collision of longitudinal and/or transverse origin, where the obstacle, created by a vehicle moving parallel to the trajectory thereof, is present on the trajectory and the obstacle that interferes with the trajectory comes from a direction transverse to it.

For example, the Codice della Strada (Italian Road Code) in Italy intervenes by imposing the restrictions that serve to reduce the number or the danger level of conflict situations. It is always entrusted to the driver the verification of the actual conditions of transvers and longitudinal safety ${ }^{1}$ with respect to its trajectory.

1 Actually, in terms of legal constraints or technical constraints of the actual level of the abatement average speed for vehicular lane/roadway, according to the legislative decree n. 285 of 30 April 1992 and to the conversion law no. 214 of 1 August 2003 (published in Official Gazette no. 186 of 12 August 2003 - SO n. 133), the terms of safety and security are coincident. We will use the definition for each term of safety. 
Ultimately, the driver is constrained by the need to secure coexistence of the three components of the transport system: road, vehicle and environment in which the safety gear is therefore linked to the individual arbitrary superimposed on a common behavioral basis $[3,5,10,12,13]$.

Below, you will be given a table which calculates the safety distance, starting from the parameters that determine the stopping distance, the reaction time of the individual vehicle driver and the stopping time, as in Siuhi and Kaseko [13], adhering to the law laid down by the Codice della Strada (Italian Road Code) art. 149.

To face the problem of the economic evaluation of profitability in section/sector it is necessary to choose the modeling more responsive to the descriptive criteria of efficiency and cost of proceedings. From the direct observation and video footage of the phenomenon of motorway traffic on highways A4 from Brescia-Est to Padova-Ovest and A31 from Vicenza to Piovene Rocchette, in September 2003, reinforced by the acquisition of data from ground loops, we select, for the introduction of the more efficient economic model of profitability, the approach of multi-lane and multi-population models, for the following reasons:

- the motorway traffic in the central days of the week for the mitigated seasonality, for the central hours of the day represents the stationary time series

- the motorway traffic in the lane, as in Duderstadt J.S., Martin W.R. [14], is comparable, in terms of imperturbability, in the absence of viscosity ${ }^{2}$, to the dynamic flow incompressible (as vehicular safety distances) of a fluid contained in a pipeline.

It is considered a large spatial-temporal scale resulting from the observation of the phenomenon of traffic or congestion carried out in a far point, so as to absorb the road vehicles by the indistinct non molecular microparticles. In this case the density is retained as a continuous distribution, since it does not conflict with a distance similar to the intraparticle on the distance of vehicular safety.

Moreover, on the condition of equal distributive continuity in the fluid dynamics (e.g. as in Quartapelle L., Auteri, F. [15]), it should be also assumed the conservation of the number of cars in a section/sector without exits or entrances, arriving thus to a conservation mathematical law similar to the law of fluid dynamics conservation. On this condition it can be affirmed that the number of cars is conserved and, if there is a quantity that is conserved, then one speaks of the law of conservation.

When the motion is stationary, the speed $v$ at every point of the space of the dynamic incompressible flow is constant in time, that is, each vehicle-particle that passes through any point of the pipeline it always does so with the same speed in its form, in its direction and in its orientation.

2 The absence of viscosity means that there are no actions between tangential fluid elements in contact.
Thus, treating the phenomenon from the point of Eulerian view, instead of describing the history of each particle of the fluid traffic, we evaluate the density, the pressure-safety distance and vehicular-particle speed in every point of the space occupied in each successive instant (as in Kühne R., Michalopoulos P. [16]): the reference is made to the so-called control volume, e.g. to the region of space which at different instants is going to be occupied by different vehicles- point-particles.

It is possible, at the end, to affirm that for the stationary motion $^{3}$ only one flow line for each point of the vehicular fluid exists and that the set of lines of vehicular flow is fixed in time ${ }^{4}$. The lines of vehicular flow, e.g., the trajectories that follow the vehicles-point-particles, can also not be straight, but will always run constant in time ${ }^{5}$ (e.g. see in Kundu P.K., Cohen I.M. [17]).

In the tabular representation of Figure 1 we verify that, at the maximum speed of the motorway code in Italy at 130 $\mathrm{km} / \mathrm{h}$ (normally), the contents of vehicles in section/sector, with full respect of safety distances, which are the theoretical minimum condition of the dot-vehicular numerosity, there are 31 dot-vehicles for a section/sector of 3.000 linear conventional meters with vehicular widespread filling at constant velocity (homotachic traffic).

It is understandable, then, that the maximum expressible profitability of the section for members of the motorway concession, given by the ROE (return on equity), which is the result of the ratio between net profit and equity, depends entirely on the vehicles of that section temporally defined.

Each measure, thus, able to intervene in a natural way in terms of perturbation on the sections/routes due to the inclusion of the fixed or mobile (construction) road yards as well as crashes or weather events, or artificially, including the legal constraints or technical constraints of the actual level abatement of the average speed for vehicular lane/roadway, affects the technical-economic productivity received from the vehicles in section and changes the business profitability, altering, at the end of the year, the profit and loss account and the revenue side of the motorway company dealership.The problem is anything but laughable.

Results of operations for typical exercises, as the project financing design for the periods of useful life of the work, always remain dependent on operating revenue. It is strategic, therefore, to provide the design of a techno-economic model of productivity which takes under control in the form of virtue, the basic parameters of the business management of the motorway sections/routes.

3 It is said in stationary flow, when the speed of the fluid, being able to vary from point to point, runs constant over time at each point.

4 Lighthill M.J., Whitham J.B. and Richards P. G., borrowed their LWR method, the partial differential equations known as Euler or Navier-Stokes equations that describe the flow of water, expressing the conservation of mass, momentum and energy as equivalent to the dynamics of the flow of traffic.

5 http://en.wikipedia.org/wiki/Fluid_dynamics. 


\begin{tabular}{|c|c|c|c|c|c|c|c|}
\hline & $\mathrm{A}$ & $\mathrm{B}$ & $\mathrm{C}$ & $\mathrm{D}$ & $\mathrm{E}$ & $\mathrm{F}$ & G \\
\hline & $\begin{array}{c}\text { Speed in } \\
\mathrm{Km} / \mathrm{h}\end{array}$ & $\begin{array}{c}\text { Average response } \\
\text { time }=\text { reaction } \\
\text { "space" in meters }\end{array}$ & $\begin{array}{l}\text { Standard time of } \\
\text { arrest }=\text { Space } \\
7 / 10 \text { second }\end{array}$ & $\begin{array}{l}\text { Stopping distance in } \\
\text { meters }=\mathrm{V}^{\wedge} 2 / 2 \mathrm{G} \\
\left(\mathrm{g}=9 \mathrm{~m} / \mathrm{s}^{\wedge} 2\right)\end{array}$ & $\begin{array}{l}\text { TOTAL stopping } \\
\text { distance in meters }\end{array}$ & $\begin{array}{l}\text { Vehicles } \\
\text { in section }\end{array}$ & $\begin{array}{c}\text { Length / section } \\
\text { of motorway in } \\
\text { meters }\end{array}$ \\
\hline 1 & 10 & 1,9 & $2 / 3$ & 0,4 & 2,4 & 1.264 & 3.000 \\
\hline 2 & 20 & 3,9 & $2 / 3$ & 1,7 & 5,6 & 535 & \\
\hline 3 & 30 & 5,8 & $2 / 3$ & 3,9 & 9,7 & 310 & \\
\hline 4 & 40 & 7,8 & $2 / 3$ & 6,9 & 14,6 & 205 & \\
\hline 5 & 50 & 9,7 & $2 / 3$ & 10,7 & 20,4 & 147 & \\
\hline 6 & 60 & 11,7 & $2 / 3$ & 15,4 & 27,1 & 111 & \\
\hline 7 & 70 & 13,6 & $2 / 3$ & 21,0 & 34,6 & 87 & \\
\hline 8 & 80 & 15,6 & $2 / 3$ & 27,4 & 43,0 & 70 & \\
\hline 9 & 90 & 17,5 & $2 / 3$ & 34,7 & 52,2 & 57 & \\
\hline 10 & 100 & 19,4 & $2 / 3$ & 42,9 & 62,3 & 48 & \\
\hline 11 & 110 & 21,4 & $2 / 3$ & 51,9 & 73,3 & 41 & \\
\hline 12 & 120 & 23,3 & $2 / 3$ & 61,7 & 85,1 & 35 & \\
\hline 13 & 130 & 25,3 & $2 / 3$ & 72,4 & 97,7 & 31 & \\
\hline 14 & 140 & 27,2 & $2 / 3$ & 84,0 & 111,2 & 27 & \\
\hline 15 & 150 & 29,2 & $2 / 3$ & 96,5 & 125,6 & 24 & \\
\hline 16 & 160 & 31,1 & $2 / 3$ & 109,7 & 140,9 & 21 & \\
\hline 17 & 170 & 33,1 & $2 / 3$ & 123,9 & 156,9 & 19 & \\
\hline 18 & 180 & 35,0 & $2 / 3$ & 138,9 & 173,9 & 17 & \\
\hline 19 & 190 & 36,9 & $2 / 3$ & 154,7 & 191,7 & 16 & \\
\hline 20 & 200 & 38,9 & $2 / 3$ & 171,5 & 210,4 & 14 & \\
\hline
\end{tabular}

Figure 1. Table of legal speeds, stopping space and time, under conditions of normal weather and for the vehicles put in accordance with the Italian Road Code (with "International Auxiliary Language" number notation)

It is evident that under conditions of safe driving, the paying vehicles in platoons/currents with continuous flow into sections/routes, for normal weather conditions, a critical density (in Musolino G., Vitetta A. [18]) which is coincident with the maximum legal speed, the revenue from the technique production is that enrolled in the revenue statement of the company in terms of optimality and it is the minimum compatible with the survival of the asset. In practice, if we consider the firms profits and the management of the road sections/routes which are dependent on the vehicular speed in the legal conditions of legality, it may be that the same speed is a constraint on the revenue under discussion.

On the other hand, the attractiveness of the infrastructure, that is the choice that makes the driver in advance for the commitment of the street, derived from the maximum speed from the vehicle and expressible feasible/desirable by the driver, compared to the same maximum speed expressible by the vehicle on the alternative road infrastructure (freeway, ordinary road, etc..).

Similarly to the classical bimodal model, the expression that defines the drivers of vehicles who commit any infrastructure road/motorway, is of the type:

$$
P_{i j}^{h}\left(I_{n}\right)=\frac{T_{i j}^{h}}{T_{i j}}=\frac{e^{-\left(\beta C_{i j}^{h}\right)}}{\sum_{k} e^{-\left(\beta C_{i j}^{k}\right)}}
$$

with:

$\mathrm{K}=1,2, \ldots . \mathrm{M} \quad\left[\mathrm{M}=\right.$ modal cut $/$ class of road vehicles $\left.{ }^{6}\right]$ having indicated with:

$P_{i j}^{h}$ the fraction of trips between the input section $i$ and section $j$ in the output mode made/class $h$ infrastructure function $\left(I_{n}\right)$ committed

$C_{i j}^{h}$ a composite function of the characteristics related to the movement with the same module/class $\mathrm{h}$ shift between the input $i$ and the output section in section $j$

$\mathrm{k}$ refers to the way of traveling between the alternative modes $m$

$\beta$ is a parameter that depends on the experimental conditions of the traffic in the section/sector (viscosity of the system) and refers to the level of service offered by the infrastructure manager

$T_{i j}^{h}$ the total displacement between the input section $\mathrm{i}$ and section $\mathrm{j}$ made in the output mode/class $\mathrm{h}$

$T_{i j}$ the total displacement between the input $\mathrm{i}$ and the output section in section $\mathrm{j}$ performed in all modes/vehicle classes

6 The objective of the modal cutting stage is to determine the value $M_{i j}{ }^{k m}$ or the proportion of displacements made by the individuals of the $\mathrm{k}^{\text {th }}$ class, from the entrance area of the section $i$ to the exit area of the section $j$, with the way of transport vs. class of the vehicle $m$, defined as the value $T_{i j}{ }^{k}$. And to estimate the proportions $M_{i j}{ }^{k m}$ one resorts to probabilistic models, and in literature two types of models are usually used, or relating to analysis of aggregate type (such as separation models), or relating to disaggregated structures. 


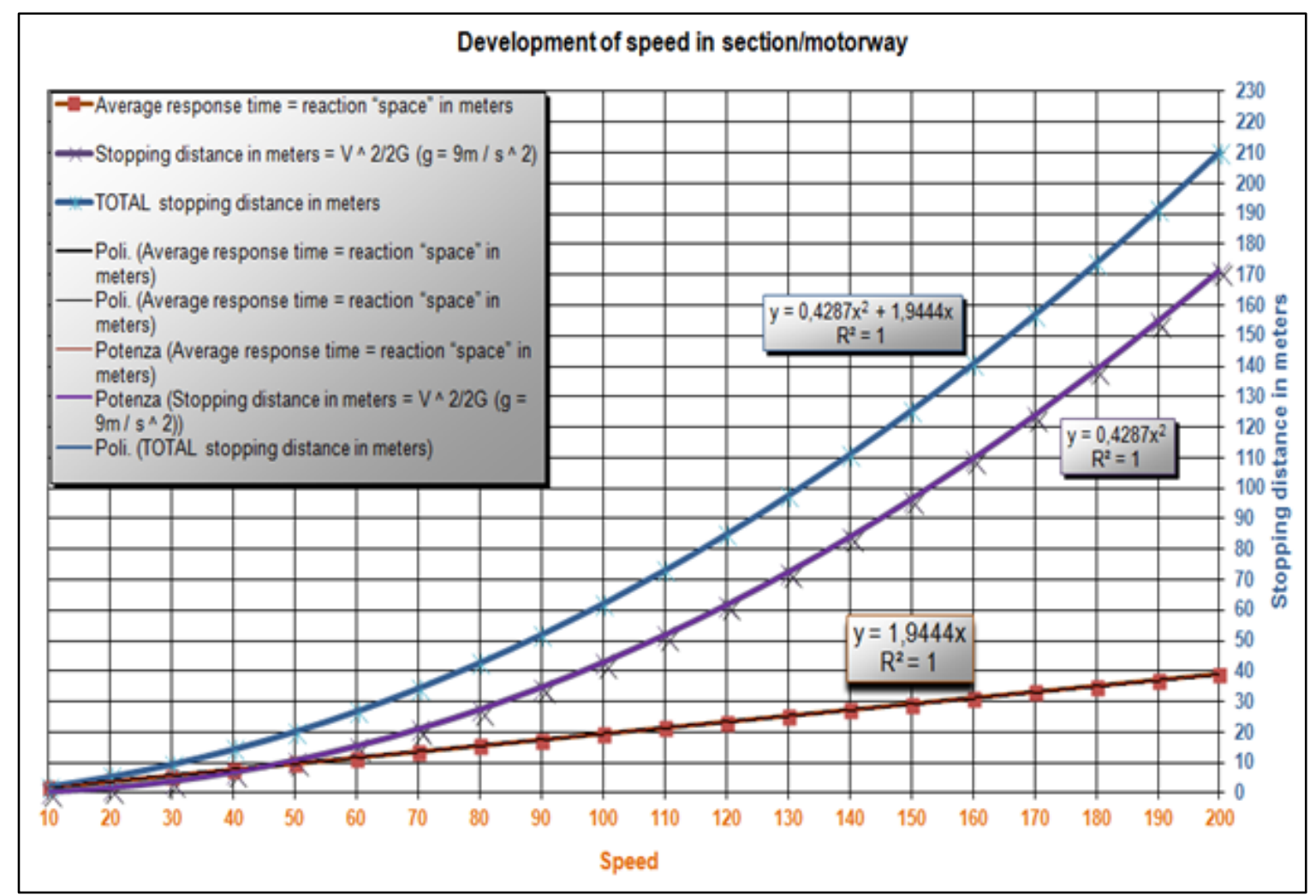

Figure 2. Graphical representation of the polynomial space vs. time with the prediction "polynomial of order 2" equations and goodness of fitting (with "International Auxiliary Language" number notation)

The classic bimodal Logit (see in Anas A. [19]), represented above, shows some interesting properties, in particular:

- determines the generation of an S-curve widening of the competitive gap of one mode or the other, as for the empirical curves named diversion curves

- generates, for equal characteristics, the distribution of displacements which takes place between the two infrastructures, by opting for vehicles of the same class, in equal parts

- if the competitive characteristics (to choose) of the mode of displacement within the infrastructure no.1 tend to be significantly lower than that of the mode of displacement within the infrastructure no.2 (alternative to no.1), all individuals tend to move on the latter, in such case $\mathrm{P}_{\mathrm{ij}}^{\mathrm{h}}\left(\mathrm{I}_{\mathrm{n}}\right)$ will tend to 1 .

It is evident that the steady state required for the implementation of the macroscopic models of the type LWR or multi-lane and multi-population, requires a great stability of traffic and a long-term vision of the phenomenon projected.

Figure 2 graphically represents the table in Figure 1, with the theoretical trend of the speed in the motorway section, in conditions of maximum legality, highlighting the MS-Excel $2013^{7}$ polynomial equations (e.g. in De Levie R. [20] for the Excel's alghoritmic accuracy for scientific data analysis) describing the reaction time vs. space of reaction in meters and stopping distance and goodness of fit $R^{2}$.

The graph is constructed on the basis of the data in the Table of legal speeds (Figure 1) and shows the representation of the data in equations, each with its own intercept, of the three main variables (using the "International Auxiliary Language" number notation):

- in dark red, the equation of "reaction time/reaction space" in meters, calculated as the average response time, and made to correspond to $7^{10 \text { th }}$ second (the range is currently defined by various academic and applied studies on the base of the anthropo-biopsychical characteristics of the central European population and it varies from 0.45 to $1.50 \mathrm{sec}$.), whose equation (i.e in Walkenbach J., [21]) is, with $R^{2}=1$ :

$$
y=+1,9444 x
$$

- in purple, the equation of "stopping sight distance" in meters (dependent on vehicle braking level for rolling friction of the tires and on the degree of braking surface wear on the tires for sliding friction- and on the elasticity of the underlying binder), with $\frac{v^{2}}{2 g}$ for $g \approx \frac{9 m}{s^{2}}, R^{2}=1:$

$$
y=+0,4287 x^{2}+0,00 x
$$

- in blue, the equation of the "total stopping distance space" in meters, which is a result from the sum of the two preceding equations, with $R^{2}=1$ : 


$$
y=+0,4287 x^{2}+1,9444 x
$$

The theoretical equations of motion of the vehicles (in points) in the section/sector of the road are the polynomial intercepts that, already at the grade $2^{\circ}$, offer the total coverage overlapping in the model (goodness of expected fit, $\left.R^{2} \approx 1\right)$. As the model in its main and exhaustive mathematical form is already described in the graph for our analysis, we omit other specification and we go to correlate graphically the theoretical average velocity of flow (continuous) and the vehicle-particles, in section/sector. The decreasing trend of the polynomial intercepts overlaps the curve drawn with $R^{2}=0,9956 \approx 1$ and with equation $y=1.585,1 x^{-1,538}$ and it is represented in Figure 3 .

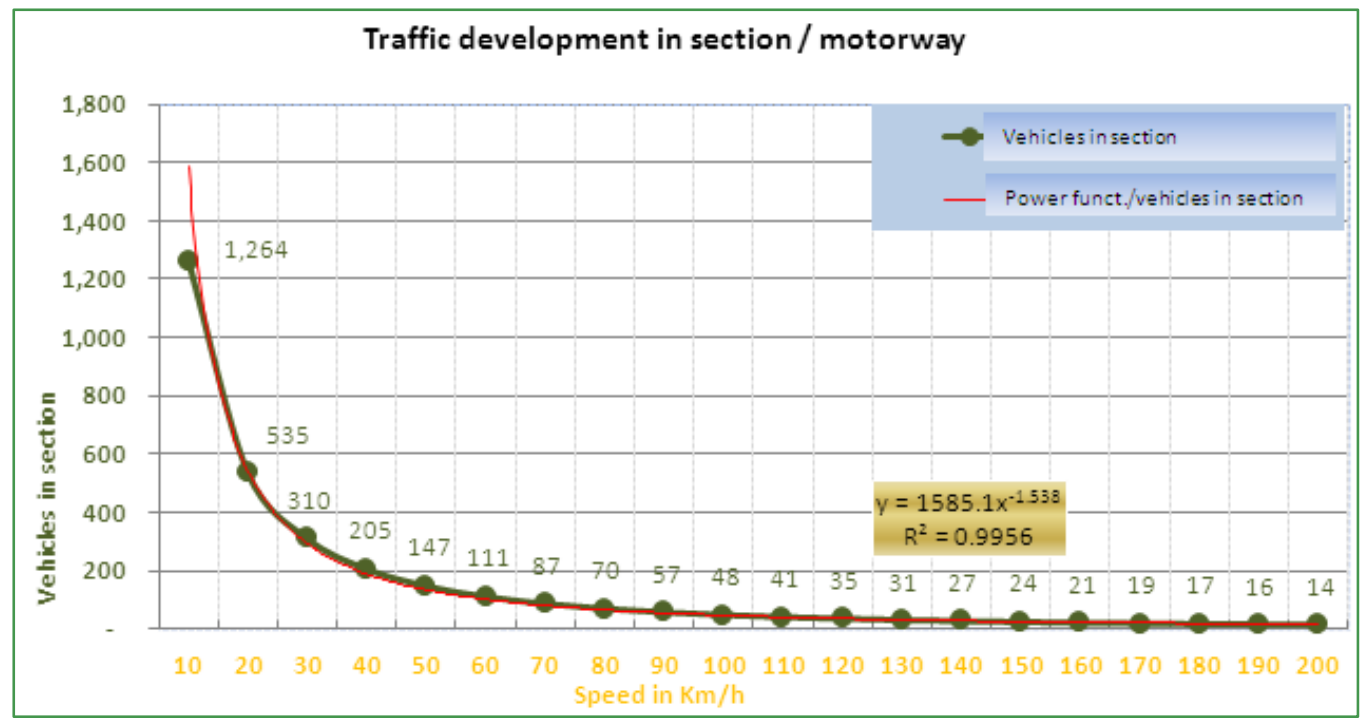

Figure 3. Graphical representation of the "polynomial of order 2" equation vehicles vs. speed and goodness of fitting (with "International Auxiliary Language" number notation)

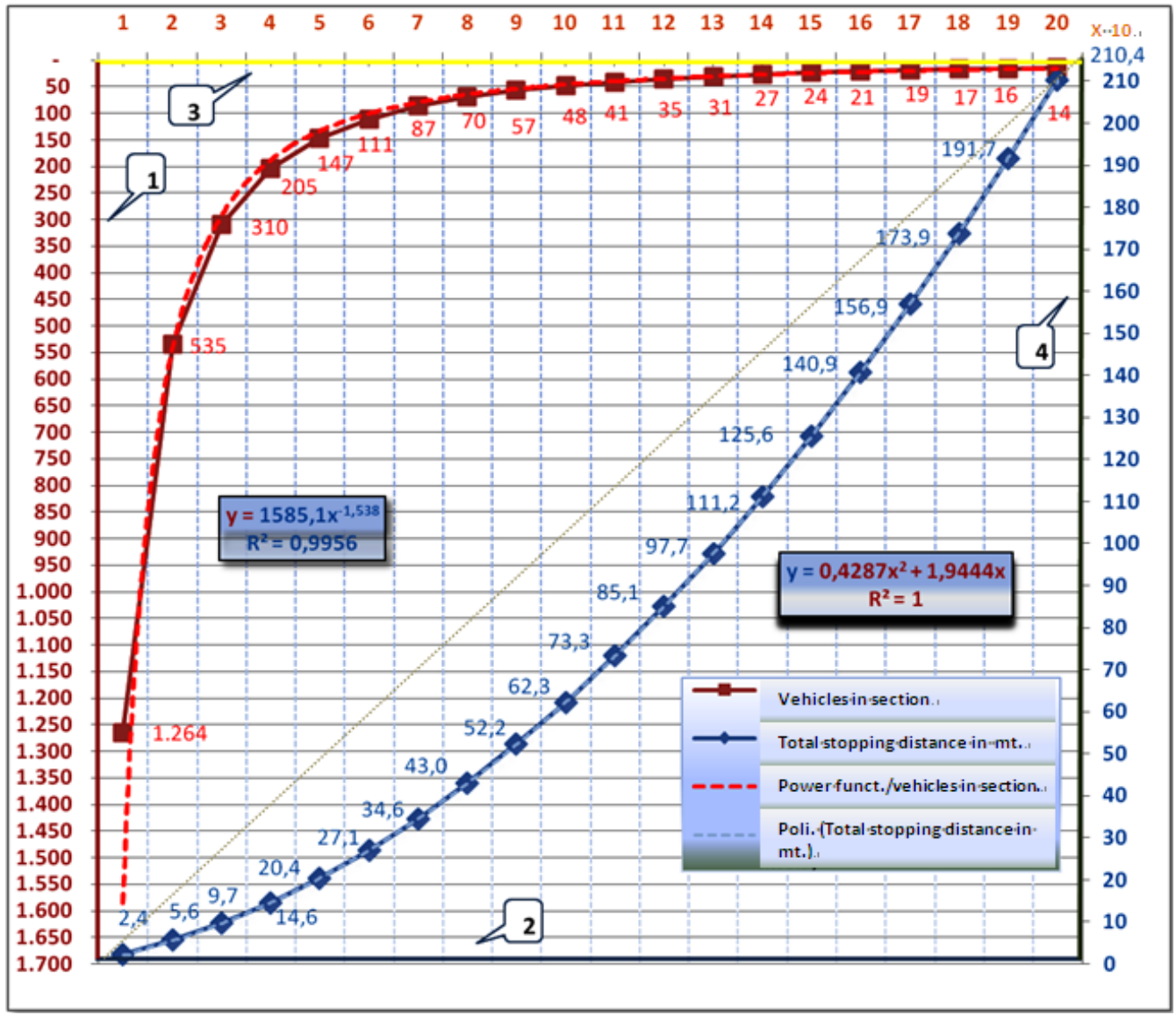

Figure 4. Graphical representation of the "polynomial of order 2" equations vehicles vs. space vs. speed and goodness of fitting (with "International Auxiliary Language" number notation) 
In Figure 4 we represent the system of equations $y=1.585,1 x^{-1,538}, y=+0,4287 x^{2}+1,9444 x$ in the first quadrant searching, subsequently, in the submitted graphical representations any points of intersection between the curves of the theoretical numerosity of punctiform vehicles in the road section/sector, of the total stopping distance in section/sector performed in the four Cartesian quadrants.

Searching for the points of intersection of the curves of the theoretical numerosity of the vehicles in motorway section/sector and of the total stopping distances in section/sector we find (using the software MATHWAY ${ }^{8}$ ):

Input interpretation

$$
\left\{\frac{1585,1}{x^{1,538}}, 0,4287 x^{2}+1,9444 x\right\}
$$

Result:

$$
\left\{\frac{1585,1}{x^{1,538}}, 0,4287 x^{2}+1,9444 x\right\}
$$

Plots:
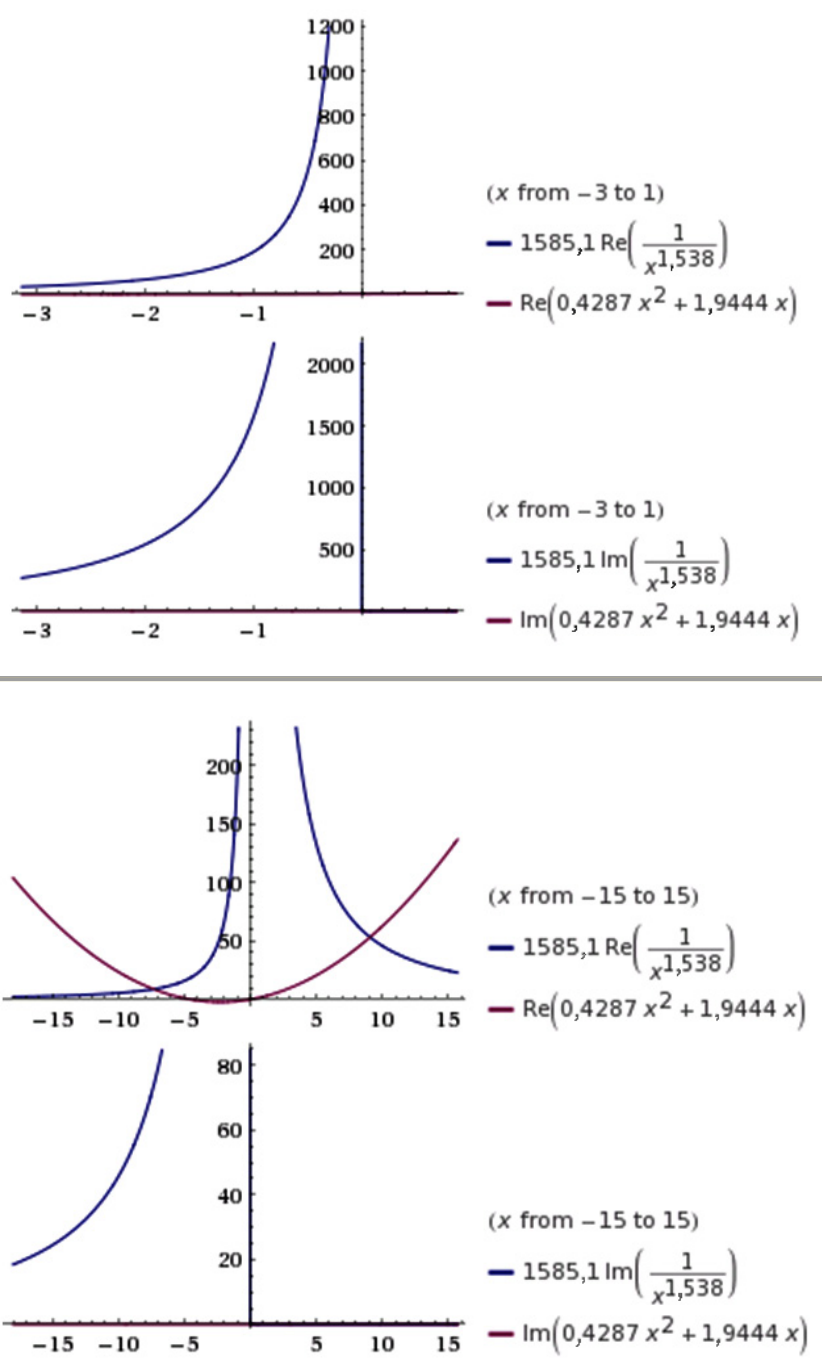

$8 \mathrm{https}: / /$ mathway.com/.
Parametric plot:

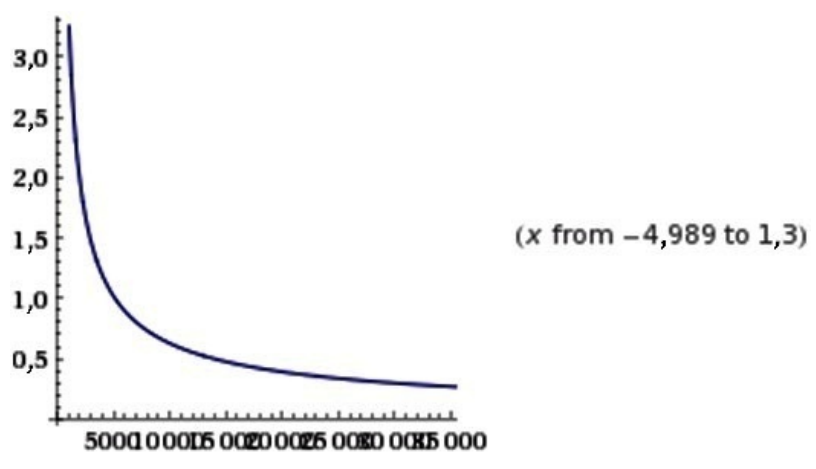

Vector length:

$$
\sqrt{\left|0,4287 x^{2}+1,9444 x\right|^{2}+\frac{2,51254 \times 10^{6}}{|x|^{3,076}}}
$$

Figure 5. Plots of the curves of the theoretical numerosity of the vehicles in motorway section/sector and related equations (with "International Auxiliary Language" number notation)

\section{Solutions:}

for $x=0$, indetermined

As the system has roots whose calculation must necessarily make use of approximations, the application of the theorem of existence of the root as the first and second uniqueness theorem of the root appears complicated and the bisection method appears difficult to apply.

It is necessary, then, the Graphical Analysis.

\section{Results}

Graphical analysis (according to Jensen C., Anderson L. [22])

The red curve of vehicles/points (we are actually computing with the "safety sections/sectors " whose boundary points together with the safety distances are represented by the point-like vehicles) in queued platoons/currents represents the best technical productivity/profitability which could be reached from the motorway section.

The blue curve of the safety distances, in its representation, is the main legal constraints (if there exists a legal speed range, as in Italy), the obstacle to maximum technical productivity.

The conditions for maximum technical productivity are represented in the Cartesian plane, by the two curves:

- in static condition of traffic at speeds equal to zero, in category 1 ( 0 to $10 \mathrm{Km})$

- in dynamic conditions of the traffic and with the maximum legal speed allowed for vehicles in category $13(120 \div 130 \mathrm{~km})$

- in dynamic traffic condition with the maximum allowable physical speed of the vehicles, in conditions of illegality $(>210 \mathrm{~km})$ - in our graph 


\section{Discussion}

\section{The paradoxes (antinomies)}

From the graphic analysis we highlight the treatable paradoxes/antinomies (as from the definitions by Van Orman Quine W. [23]), according to the theory of the constrained optimization, whose general form is:

$$
\begin{gathered}
\max C\left(x_{1}, \ldots \ldots x_{n}\right) \quad(\text { objective function) } \\
\varphi_{1}\left(x_{1}, \ldots \ldots x_{n}\right) \leq b_{1} \\
\ldots \ldots \ldots \ldots \ldots \ldots \text { (restrictions) } \\
\varphi_{m}\left(x_{1}, \ldots \ldots x_{n}\right) \leq b_{m}
\end{gathered}
$$

which represents a problem with $n$ variables and $m$ constraints. The constraints and the objective are the real functions with the vector variables and they can also be represented as constraints on the values of the variables (such as non-negativity or integrality). The constraints and the objective may be those linear of LP (Linear Optimization) and the generic model then becomes:

$$
\begin{gathered}
\max \sum_{i=1}^{n} c_{i} x_{1} \text { (objective function) } \\
\sum_{\mathrm{i}=1}^{\mathrm{n}} \mathrm{a}_{\mathrm{i}} \mathrm{x}_{1} \leq \mathrm{b}_{1} \\
\ldots \ldots \ldots \ldots \ldots \ldots(\mathrm{r} \\
\sum_{\mathrm{i}=1}^{\mathrm{n}} \mathrm{a}_{\mathrm{m}, \mathrm{i}} \mathrm{x}_{1} \leq \mathrm{b}_{\mathrm{m}}
\end{gathered}
$$$$
\text { ................ (restrictions) }
$$

Paradoxe (Antinomy) 1: it would be constituted by the driver's acceptance - in a static condition at speed equal to zero in motorway section/sector - at a safe distance equal to zero, for a total of 1.700 average punctiform vehicles treated as static units. Dividing by the average length for motorway vehicular class $(\mathrm{A}, \mathrm{B})$ it is obtained the real vehicular densitometric presence in static condition. The Cartesian expression is represented by the same axis of the ordinate (red line 1).

Paradoxe (Antinomy) 2 (the "little-train" paradox): it would be formed from the acceptance, by the driver-player, of a dynamic condition at the maximum mechanical speed permitted by the vehicles in homotachic condition and at safety distance equal to zero, for a total of 1.700 average punctiform vehicles as dynamic units. Dividing by the average length for vehicular European class (A, B) it is obtained the real densitometric presence in the dynamic condition. The Cartesian expression is represented by the same axis of abscissas (blue line 2).

Paradoxe (Antinomy) 3: (St. Petersburg's paradox) it would be constituted by the acceptance by the driver-player of a isolated vehicle, in dynamic conditions, at the maximum mechanical speed permitted, to pay a price of toll equal to the revenue equivalent of the vehicular platoon/current in the motorway section/sector. The Cartesian expression is represented by the same axis of the reciprocal abscissas (yellow line 3).

Paradoxe (Antinomy) 4: ("First Paradox Against Movement" - Zeno of Elea) it would be constituted by the acceptance of the part of drivers-players of the dynamic conditions at the maximum mechanical speed allowed at constant-velocity condition and at a safe distance varying to zero. It is a condition of crash due to an obstacle in section. The Cartesian expression is represented by the same axis of the reciprocal ordinate (green line 4).

According to the theory of utility-value there would be the indifference as one equates the two equations for

$0=1.585,1 x^{-1,538}-0,4287 x^{2}-1,9444 x$, that is not in this Cartesian plane and typically in three dimensional space, as, in this space, the large number of punctiform vehicles depends on the safety distances which depend, in their turn, on the speeds reached.

The curves obtained are rigid, and the generated graphic "eye chart" remains constant, in theoretical and maximum legality terms.

\section{The decision-making process of the driver-player}

Making the list of possible decisions that can be assumed by the driver-player it is difficult to consider "all that could happen" but, as far as possible, one keeps in mind everything that may influence the choice of the decision by the driver-player, what one could reasonably verify.

The solution of the problem is obtained by using the Decision Theory, e.g., by making the driver-player (the decision maker) to decide on the various alternative guide strategies, the immediate-future eligible "through right" and not eligible "through wrong", in the search of the pay-off line conform with its own interests, on the strategies and actions whose outcome also depends on external factors (e.g. in Menneni S., Sun C.P.D., Vortisch P. [24] that can not be predicted as scenarios but as the combination of sets of events defined in the Decision Theory as "States of Nature".

The general expression of the external factors not predictable is represented [Authors note: not here] primarily by the matrix of pay-off of "States of Nature".

The decision tree is complete, then, with the matrix of the consequences, in which the torque strategy-scenario finds the composition in the matrix of the pay-off in subject and on which we take the analysis.

Matrix1. Matrix of the pay-off

STATES OF NATURE $=$ POSSIBLE EVENTS OUT OF THE DECISION MAKER CONTROL

\begin{tabular}{|c|c|c|c|c|}
\hline Strategies vs. Actions & $\mathrm{SN}_{1}$ & $\mathrm{SN}_{2}$ & ---- & $\mathrm{SN}_{\mathrm{n}}$ \\
\hline $\mathrm{D}_{1}$ & $\mathrm{a}_{11}$ & $\mathrm{a}_{12}$ & ----- & $\mathrm{a}_{1 \mathrm{n}}$ \\
\hline $\mathrm{D}_{2}$ & $\mathrm{a}_{21}$ & $\mathrm{a}_{22}$ & ----- & $\mathrm{a}_{2 \mathrm{n}}$ \\
\hline---- & ---- & ---- & ---- & ---- \\
\hline $\mathrm{D}_{\mathrm{n}}$ & $\mathrm{a}_{\mathrm{m} 1}$ & $\mathrm{a}_{\mathrm{m} 2}$ & ----- & $\mathrm{a}_{\mathrm{mn}}$ \\
\hline
\end{tabular}

With:

- $\quad \mathrm{a}_{\mathrm{ij}}$ : the pay-off from the decision $\mathrm{D}_{\mathrm{i}}$ when the state of nature $\mathrm{SN}_{\mathrm{j}}$ is determined

- $\quad \mathrm{D}_{\mathrm{i}}: \mathrm{i}^{\text {th }}$ decision to be taken

$\mathrm{D}_{\mathrm{i}}$ decision has a dominion over a decision $\mathrm{D}_{\mathrm{k}}$ when:

$$
a_{i j} \geq a_{k j}, j=1, \ldots, n \text {; }
$$

Then: 
- for all states of nature $\mathrm{SN}_{\mathrm{j}}$ the consequences associated with $D_{i}$ are not worse than those associated with $D_{n}$

- there is at least one state of nature in which the consequence associated with $\mathrm{D}_{\mathrm{i}}$ is better than another

At this point, the decision dominated is discarded ${ }^{9}$ and the decision $\mathrm{D}_{\mathrm{i}}$, dominant, is permissible.

We define, therefore, a strategy as absolutely dominant strategy in case when, regardless of the strategy of the rival, it guarantees the absolute maximum pay-off. When the drivers-players take a dominant strategy, according to criteria of matrix effects, it is often to be defined a Nash equilibrium, e.g., when it is not convenient to any driver-player to change unilaterally the strategy and when it does not necessarily coincide with a state of optimality for both. In cases of collusion, such as fitting into the queue in the motorway lane with "normal" traffic, the collusion participants could improve their pay-off compared to the Nash equilibrium (as a bumper-to-bumper situation).

The function "consequences", as in the resolution matrix, can have the form of numbers (or less), but in any case, with two or more consequences given, the driver-player must be able to determine which result it prefers or whether there are all equivalent. Typically, a driver-player would be able to get for him the best consequence, but since he can only choose according to personal human factor and not on the scenario, he can not get to choose the consequence that he can (almost) certainly run into.

Introducing the criterion of optimality $\mathrm{K}$ and date the $\mathrm{C}$ function, one can describe the decision of the driver-player, for $C\left(D_{n}\right)=C\left(D_{1}, S N_{1}\right), C\left(D_{1}, S N_{2}\right) \ldots$ as:

$$
D_{n}=K C\left\lfloor D_{n}\right\rfloor
$$

A driver-player decides according to the maximin criterion (e.g. in Wald [25]), corresponding to the most pessimistic hypothesis of the loss of opportunities in relation to the response of the other drivers-players, when he calculates and considers the minimum pay-off, as a synthesis of values, for each strategy in availability, and chooses the strategy that involves "less worse" or "limitation of losses," $C\left(D_{1}, S N_{1}\right), C\left(D_{1}, S N_{2}\right) \ldots$ as:

$$
K\left\lfloor C\left(D_{n}\right)\right\rfloor=\min _{\mathrm{SN}} C\left(D_{n}, S N_{n}\right)
$$

A driver-player decides according to the criterion

9 According to the theory of decisions under conditions of uncertainty, the decision rules include 4 exclusive criteria/decision-making strategies in general, in relation to the probability of the scenarios:

- Criteria of matrix effects, as:

maximin criterion

maximax criterion

minimax criterion

Hurwicz criterion

- Criteria of probability of the scenario as:

criterion of the maximum probability

- Bayesian Criteria as:

Criterion of the expected value

the mean-variance criterion (Laplace)

Criterion of loss of opportunity expected (regret)

- Criteria of expected utility maximax, corresponding to the more optimistic hypothesis of buying of the opportunity, in relation to the response of the other drivers-players, when he calculates and considers the pay-off maxinun, as a synthesis of values for each strategy in availability and chooses the strategy that behaves "at most", for $C\left(D_{1}, S N_{1}\right), C\left(D_{1}, S N_{2}\right) \ldots$ as:

$$
K\left\lfloor C\left(D_{n}\right)\right\rfloor=\max _{\mathrm{SN}} C\left(D_{n}, S N_{n}\right)
$$

A driver-player decides according to the minimax criterion, corresponding to the less pessimistic hypothesis of the loss of opportunities, in relation to the response of other drivers-players, when one calculates and considers as a synthesis of values for each strategy in availability, the minimum pay-off of the maximum loss and chooses the strategy that behaves "better", for $C\left(D_{1}, S N_{1}\right), C\left(D_{1}, S N_{2}\right) \ldots$ as:

$$
K\left\lfloor C\left(D_{n}\right)\right\rfloor=\max _{\mathrm{SN}} C\left(D_{n}, S N_{n}\right)-a_{m n}
$$

A driver-player decides for each strategy in availability according to the criterion of Hurwicz (described in Jaffray J.Y., Jeleva M. [26]), in relation to the response of the other drivers-players, when he considers and calculates, as a synthesis of values, either the better consequence or the worst one, computed according to the shadow price (marginal rate of substitution) to $C\left(D_{1}, S N_{1}\right), C\left(D_{1}, S N_{2}\right) \ldots$ as:

$$
\begin{gathered}
K\left\lfloor C\left(D_{n}\right)\right\rfloor= \\
\Gamma \max _{\mathrm{SN}} C\left(D_{n}, S N_{n}\right)+(1-\Gamma) \min _{S N} C\left(D_{n}, S N_{n}\right)
\end{gathered}
$$

where:

$$
\text { - } \quad(0<\Gamma<1)
$$

A driver-player decides for each strategy in availability according to the criterion of maximum probability, in relation to the response of the other drivers-players, when he considers and calculates, as a synthesis of values, the probably better consequence, the greater probabilistic convenience, for $C\left(D_{1}, S N_{1}\right), C\left(D_{1}, S N_{2}\right) \ldots$ as:

$$
\begin{gathered}
K\left\lfloor C\left(D_{n}\right)\right\rfloor= \\
P\left(\Gamma \max _{S N} C\left(D_{n}, S N_{n}\right)+(1-\Gamma) \min _{S N} C\left(D_{n}, S N_{n}\right)\right)
\end{gathered}
$$

where:

$$
\begin{aligned}
& \text { - } \quad(0<\Gamma<1) \\
& \text { - } \quad(0<P<1)
\end{aligned}
$$

In the choice of the driver-player are not directly applicable the Laplace criteria (as the equiprobability of a car crash to happen, but in reality it is merely forcing, as it means to assume driving behaviors repeatable according to the St. Petersburg paradox) and Savage criteria ("of regret" which is determined solely by the cost of the crash, thus constraining the driver to make a testament before traveling, as they did in the Middle Ages and in the timing of "road extortionist"10). In these cases the adoption of decisions by the driver-player

10 A sort of a illegal Italian (it. "passatore") Robin Hood 
on the sections/sectors concerns, for two decision-making models, the criteria for safety and car crash rates (with irreversible consequences on safety), or the acquisition of exclusive benefits related to the vehicular run for the competitive purposes (as in the sports competitions and on the racetrack).

The example, proposed in order to make clear the explained above, sets out the decision of the driver-player late for an appointment to increase the speed to get before at a business meeting for 1,00 million $€$ or not to increase the speed risking of losing the deal being thus considered unreliable.

In this situation, increasing the speed the driver-player will arrive on time and (maybe) make the deal but it will happen (maybe) a car crash (if it was thought of the driver-player as not mortal). The driver-player, arriving late (maybe), will lose the deal but he will save himself (maybe) from the crash.

The alternatives, are, therefore, with $\mathrm{W}_{\mathrm{i}, \mathrm{j}}=$ cost of the car crash such as loss of opportunity

Matrix 2. Matrix of the loss of opportunity

\begin{tabular}{|c|c|c|}
\hline \multicolumn{3}{|c|}{$\begin{array}{c}\text { STATES OF NATURE }=\text { POSSIBLE EVENTS OUT OF THE } \\
\text { DECISION MAKER CONTROL }\end{array}$} \\
\hline Strategies vs. Actions & $\begin{array}{c}\mathrm{SN}_{1}=\text { not having a } \\
\text { car crash }\end{array}$ & $\begin{array}{c}\mathrm{SN}_{2}=\text { having a } \\
\text { car crash }\end{array}$ \\
\hline $\mathrm{D}_{1}=$ run at legal speed & $\mathrm{W}_{11}$ & $\mathrm{~W}_{12}$ \\
\hline $\mathrm{D}_{2}=$ increase the speed & $\mathrm{W}_{21}$ & $\mathrm{~W}_{22}+\mathrm{W}_{\text {life }}$ \\
\hline
\end{tabular}

Let us assume that one can not assign any probability to $\mathrm{SN}_{1}$ and $\mathrm{SN}_{2}$ remaining, so, in a state of complete information ignorance.

In case of cost $\mathrm{W}_{11}$, one has $\mathrm{W}_{11}=0$ as the compliance with legal standards reduces to zero the number of crashes.

In case of cost $\mathrm{W}_{22}$, it must be added, in addition to the cost of repairing the vehicle after a car crash, the social cost of injury/loss of life, so $\mathrm{W}_{22}+\mathrm{W}_{\text {life }}$.

Reporting the Cost table, reparameterized as:

Matrix 3. Matrix of the Cost, riparametrized

\begin{tabular}{|c|c|c|}
\hline \multicolumn{3}{|c|}{$\begin{array}{c}\text { STATES OF NATURE EVENTS = POSSIBLE EVENTS OUT OF } \\
\text { THE DECISION MAKER CONTROL }\end{array}$} \\
\hline Strategies vs. Actions & $\begin{array}{l}\mathrm{SN}_{1}=\text { not having a } \\
\text { car crash }\end{array}$ & $\begin{array}{l}\mathrm{SN}_{2}=\text { having a } \\
\quad \text { car crash }\end{array}$ \\
\hline $\mathrm{D}_{1}=$ run at legal speed & $\begin{array}{c}\mathrm{W}_{11}=\text { no business } \\
\text { deal }\end{array}$ & $\begin{array}{c}\mathrm{W}_{12}=\text { no } \\
\text { business deal }\end{array}$ \\
\hline $\mathrm{D}_{2}=$ increase the speed & $\begin{array}{c}\mathrm{W}_{21}=\text { do business } \\
\text { deal }\end{array}$ & $\begin{array}{c}\mathrm{W}_{22}+\mathrm{W}_{\text {life }}= \\
\text { never business } \\
\text { deal }\end{array}$ \\
\hline \multicolumn{3}{|c|}{ PARAMETRIZED } \\
\hline \multicolumn{3}{|c|}{$\begin{array}{c}\text { STATES OF NATURE }=\text { POSSIBLE EVENTS OUT OF THE } \\
\text { DECISION MAKER CONTROL }\end{array}$} \\
\hline Strategies vs. Actions & $\begin{array}{l}\mathrm{SN}_{1}=\text { not having a } \\
\text { car crash }\end{array}$ & $\begin{array}{l}\mathrm{SN}_{2}=\text { having a } \\
\text { car crash }\end{array}$ \\
\hline $\mathrm{D}_{1}=$ run at legal speed & $\mathrm{W}_{11}=0,00 €$ & $\mathrm{~W}_{12}=0,00 €$ \\
\hline $\mathrm{D}_{2}=$ increase the speed & $\mathrm{W}_{21}=-1,00 \mathrm{~m} \ln €$ & $\begin{array}{c}\mathrm{W}_{22}=0,00 €+ \\
\mathrm{W}_{\text {life }}\end{array}$ \\
\hline
\end{tabular}

\section{Criterion of pessimism}

Matrix 4. Matrix of the Criterion of pessimism

\begin{tabular}{|c|c|}
\hline \multicolumn{2}{|c|}{$\begin{array}{c}\text { STATES OF NATURE }=\text { POSSIBLE EVENTS OUT OF THE } \\
\text { DECISION MAKER CONTROL }\end{array}$} \\
\hline Strategies vs. Actions & $\mathrm{SN}_{2}=$ having a car crash \\
\hline $\mathrm{D}_{1}=$ run at the legal speed & $\mathrm{W}_{12}=0,00 €$ \\
\hline $\mathrm{D}_{2}=$ increase the speed & $0,00 €+\mathrm{W}_{\text {life }}$ \\
\hline
\end{tabular}

Since the cost of the crash is greater than zero it should be adopted the hypothesis of $\mathrm{D}_{1} \mathrm{SN}_{1}$

\section{Criterion of optimism}

Matrix 5. Matrix of the Criterion of optimism

\begin{tabular}{|c|c|}
\hline $\begin{array}{c}\text { STATES OF NATURE }=\text { POSSIBLE EVENTS OUT OF THE } \\
\text { DECISION MAKER CONTROL }\end{array}$ \\
\hline Strategies vs. Actions & $\mathrm{SN}_{1}=$ not having a car crash \\
\hline $\mathrm{D}_{1}=$ run at legal speed & $\mathrm{W}_{11}=0,00 €$ \\
\hline $\mathrm{D}_{2}=$ increase the speed & $\mathrm{W}_{21}=-1,00 \mathrm{mln} €$ \\
\hline
\end{tabular}

The criterion of optimism advises to adopt the solution $\mathrm{D}_{2} \mathrm{SN}_{1}$ out of the state of law and assuming, thus, the risk $\left(\mathrm{W}_{21}=-1,00\right.$ million $€$ as the yields of the deal is the inverse additive that is the opposite of the cost bearable).

\section{Hurwicz criterion and sensitivity study}

Introducing a variable, solution criteria with the value of $\propto$, as a coefficient of optimism/risk tendency, which the driver-player should select, while the $W_{\text {life }}$ is a value generated by the environment, therefore uncontrollable, one can advance to a sensitivity study with:

- $\mathrm{Z}_{1}=\propto \mathrm{W}_{11}+(1-\propto) \mathrm{W}_{12}$

- $\mathrm{Z}_{2}=\propto \mathrm{W}_{21}+(1-\propto)\left(\mathrm{W}_{22}+\mathrm{W}_{\text {life }}\right)$

which are developed as:

- $\mathrm{D}_{2}>\mathrm{D}_{1} \rightarrow \mathrm{Z}_{2}>\mathrm{Z}_{1} \rightarrow \propto \mathrm{W}_{21}+(1-\propto)\left(\mathrm{W}_{22}+\mathrm{W}_{\text {life }}\right)>\mathrm{W}_{11}$ $+(1-\propto) \mathrm{W}_{12}$

Matrix 6. Matrix of the Hurwicz criterion

\begin{tabular}{|c|c|c|}
\hline \multicolumn{3}{|c|}{$\begin{array}{c}\text { STATES OF NATURE }=\text { POSSIBLE EVENTS OUT OF THE } \\
\text { DECISION MAKER CONTROL }\end{array}$} \\
\hline Strategies vs. Actions & $\begin{array}{l}\mathrm{SN}_{1}=\text { not having a } \\
\text { car crash }\end{array}$ & $\begin{array}{l}\mathrm{SN}_{2}=\text { having a } \\
\text { car crash }\end{array}$ \\
\hline $\mathrm{D}_{1}=$ run at legal speed & $\mathrm{W}_{11}=\propto * 0,00 €$ & $\begin{array}{c}\mathrm{W}_{12}=(1-\propto)^{*} \\
0,00 €\end{array}$ \\
\hline $\mathrm{D}_{2}=$ increase the speed & $\begin{aligned} \mathrm{W}_{21}= & -\propto * 1,00 \\
& \operatorname{mln} €\end{aligned}$ & $\begin{array}{l}(1-\propto) *(0,00 € \\
\left.+\mathrm{W}_{\text {life }}\right)\end{array}$ \\
\hline
\end{tabular}

And one finds solutions as:

- $\mathrm{Z}_{1}=\propto \mathrm{W}_{11}+(1-\propto) \mathrm{W}_{12}=0$

- $\mathrm{Z}_{2}=\propto \mathrm{W}_{21}+(1-\propto)\left(\mathrm{W}_{22}+\mathrm{W}_{\text {life }}\right)=-\propto * 1,00+(1-\propto)$ $\mathrm{W}_{\text {life }}$

Per:

- $\mathrm{Z}_{1}<\mathrm{Z}_{2}: 0<-\propto * 1,00+(1-\propto) \mathrm{W}_{\text {life }} ;+\propto /(1-\propto)<$ $\mathrm{W}_{\text {life }}$ 


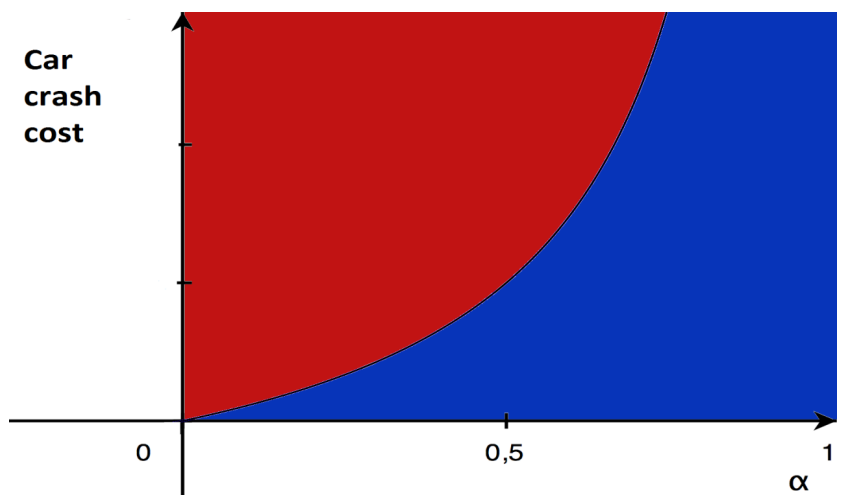

Figure 6. Graphical representation of risk propension. Sensitivities of $\alpha$ and $\mathrm{W}_{\text {life }}$. Prevalence of the alternative (with "International Auxiliary Language" number notation)

The curve of Figure 5 tends to $+\infty$ for $\propto \rightarrow 1$ which is vertical asymptote for the function $y=+\propto /(1-\propto)$.

The graphical representation provides us the following insights:

- For high risk propensity $(\propto \rightarrow 1)$ in respect of a perceived cost of the bearable crash and inhibiting by consciousness the social and economic cost of the crash, the driver-player will convenient to adopt the decision $\mathrm{D}_{2}$

- For low risk propensity $(\propto \rightarrow 0)$ in respective of a perceived cost of the unbearable incident and urging by consciousness the social and economic cost of the crash, the driver-player will convenient to adopt the decision $\mathrm{D}_{1}$

- Growing the risk, the curve describes, along its line of threshold, the exponential strategies, which are the inhibitive and soliciting for the individual conscience.

So, at the end of the behavioral analysis shown through the decision theory, the decision problem, that the driver-player takes, appears more and more as a problem of uniform matroid (in the sense of Oxley, J. G. [27]): the data of $n$ individual safety situations of cost $\mathrm{W}_{\mathrm{i}}$, extract a subset of $\mathrm{k}$ individual safety situations of minimum total cost. Since the structure of the problem is matroidal, it could be applied the greedy algorithm ${ }^{11}$ (the test of independence is merely to assess that the current subset does not exceed the cardinality $\mathrm{k}$ ). In other words, it makes itself k-individual objects of safety of minimum cost (as in Arcaini P., Cordone R.[28]).

If the values are uncertain and defined in intervals $D_{n}=K C\left\lfloor D_{n}\right\rfloor$ or $D_{n}=K C\left\lceil D_{n}\right\rceil$, one can optimize the absolute strength in polynomial time, since it is sufficient to consider the extreme values (minimum and maximum) of all safety costs and it is not necessary to consider all combinations, thanks to dominance rules seen above. If the values are defined as scenarios, or the robust deviation is optimized, the problem results as NP-complete by reduction, from Partition (as in Averbakh I., Lebedev V. [29]) problem.

In a different alternative way, a criterion applicable to the

$11 \mathrm{http}: /$ disi.unitn.it/ montreso/asd/lucidi/14-greedy-up.pdf decisions of the driver of the vehicle results from the dichotomous assessment of the time spent in the car and the speed that can be expressed by the driver in respect of the value of time spent in the car; so as respect the value given by the social stratum to which the driver belongs in the time to be spent in the car. But that topic is beyond this article, as it relates to the analysis of the demand. There is no a driver behavior attributable to an interpretable model in the medium-long term but it is contingent for the situation and for the external generated event.

At this point, there are the external factors that regulate the circulation and the traffic in sections/sectors of motorways, bearing in mind the fluid dynamics approach, e.g. applying the equations of continuity and of the mass balance. To this end, it is worth to remember how much influence the Bernoulli theorem can have on the equation of continuity when applied to land transport ${ }^{12}$ and linked to the speed of downflow of Torricelli.

The final report of the study carried out by the author, as designer, in 2003 at the Italian Motorway Company "Società Autostradale Brescia-Verona-Vicenza-Padova SpA", which holds the concession for the motorway A4 (from West of Brescia to East of Padova) and A 31 (from Vicenza to Piovene Rocchette), has revealed a number of factors that are related to the traffic in the section/sector, resulting in synthesis, such as:

A. Crashes, incidents and road yards

The crashes events are determined to about 50\% from the rear-end collisions, front-lateral collisions and lateral side clashes in the same lane and caused up to $15 \%$ of the loss of some materials in the roadway

- the crashes happen mainly during the day, without a precise time

- they occur in good weather

- they occur for various reasons, no one is really prevalent

- the incidents occur with greater frequency in the curved sections induced or natural (junctions)

- they happen in casual days

- the incidents are influenced by the presence of fixed road yards $(65 \%)$

- they are a bit less influenced by the presence of mobile road yards

- $\quad$ they do not involve any particular vehicles significantly

- they are distributed almost uniformly in the North and South part of the motorway A31, while they prevail rather on the East part than on the West part of the motorway A4 (8 percentage points of difference)

\section{B. Crashes and nationality}

In the absence of statistical data on the universe of vehicular traffic broken down by type of vehicle and

12 In the case of land transport it is possible to neglect the gravitational term of Bernoulli's equation as the vehicular flow lines, to which the reference is made, have approximately the same potential energy (as in Ferrarese M. $[30])$. 
nationality, it is not possible to identify with scientific methods the statistical relationship between the crashes and nationalities.

The phenomenon is evaluated, then, through a statistical procedure of rate, in absolute and relative values , noting that the foreign vehicles (mainly from the East of Europe) involved in crashes add up to $15,5 \%$ (2002).

It emerges from the operational report 2003 emerges that the incidental phenomenon seems to be really random with respect to the weather conditions, to the conditions of infrastructure and to the skills, nationality and physical conditions for drivers.

And it is necessary, then, as it was analyzed, to present a model of economic management, more than forecast, which optimizes for the subsequent approaches and for mathematical approximation, the economic result expected by the managerial decision-maker of the motorway concessionaires, who should take a decision in critical conditions, such as in the in the case of closure of tollbooths and sections/sectors due to accidents, congestion, weather adversity, long as they are properly reported events to driver-player.

This model is nominated MPCA (Italian acronym: Modello dei Parametri di Conto Autostradale - Model of Motorways Account Parameters) on the definition of the parameters of the account and it is presented in the next paragraph.

\section{A Computational Methodology: the MPCA Model to Define the Parameters of Account}

To compute the technical and economic productivity and the expected profitability of concessionaires in Italian motorway transportation, and, especially, to create an easy understanding approach for designers in the automotive industrial sector, it is designed a new model (MPCA), which runs on the spreadsheet and using the functions of PHStat 3.0-Pearson for Microsoft Office Excel 2013 (as in Karasan O.E., Pinar M.C., Yaman H. [31]).

This model consists of a table, composed of a column B in which appear the different items to be examined with the relative value assumed in the column $\mathrm{C}$ and in the nominal 48 rows, where each variable is described.

The entered values do not consider the division into class of the vehicles in transit (formal classification that is used to determine the different vehicular rates) since the coils on the ground, for the detection of vehicular traffic, from which the data are derived, record the only indistinct vehicular transit .

We describe, briefly, the variables allocated for the fields of the model, that uses the Figure 1 and Figure 6 of this article, such as databases.

DATA ENTRY: data pivot

- C4: Length of motorway section in meters

- C5: Average vehicular speed for the roadway lane and for the carriageway $(\mathrm{Km} / \mathrm{h})$
- C6: Time of observation of the section (seconds)

- C7: Unitary toll per section per vehicle class $(<=>1,30$ $\mathrm{m}$ on the front axle), "that is, how much of the total toll is spent on the road section in question (currently, the mileage Italian rate is about $0,06 € / \mathrm{km}$

- C8: Annual variable cost per section

- C9: Annual fixed cost per section

- C10: Maximum speed per section $(\mathrm{km} / \mathrm{h} 130$ or exceptionally $\mathrm{km} / \mathrm{h} 150$ )

BREAK-EVEN ANALYSIS: For entering data which are derived from the above mentioned, with the parameters provided for by the Italian Legislative Decree no. 285 of 30 April 1992 and the conversion law no. 214 of 1 August 2003 (published in Italian Republic Official Gazette no. 186 on 12 August 2003 - S.O. n. 133).

- C15: Crossing time of the section (seconds), that results as $=\mathrm{C} 4 / 1000 / \mathrm{C} 5 * 3600$

- C16: Maximum quantity of observable vehicles per roadway lane and carriageway, that results as $=\mathrm{C} 6 / \mathrm{C} 15 * \mathrm{C} 17$

- $\quad$ C17: Vehicles per section (quantity), given by =CERCA.VERT('Figure 6'!C5;'Figure 1'!\$A2:\$F21;2;VERO)

- C18: Maximum vehicle capacity per section, given by $=\mathrm{SE}(\mathrm{C} 10=130 ; '$ Figure 1'!F $\$ 14 ;$ 'Figure 1'!F \$16)

- C19: Vehicular percentage variation of the maximum speed per section, given by $=-(\mathrm{C} 18-\mathrm{C} 17) / \mathrm{C} 18$

- C20: Toll-per-section per observation time, given by $=\mathrm{C} 7 * \mathrm{C} 16$

- C21: Variable cost per section for observation time, given by $=\mathrm{C} 8 / 365 / 24 / 60 / 60 * \mathrm{C} 6$

- $\quad$ C22: Fixed costs per section per observation time, given by $=\mathrm{C} 9 / 365 / 24 / 60 / 60 * \mathrm{C} 6$

- C25: Equilibrium quantity - Break-Even Point for unitary section, given by $=\mathrm{SE}(\mathrm{O}(\mathrm{C} 7="$ ";C8="");0;C22/(C20-C21))

- C26: Revenue of equilibrium, given by $=\mathrm{C} 22 /(1-(\mathrm{C} 21 / \mathrm{C} 20))$

- $\quad$ 27: Rate of utilization of the vehicle productive capacity, which results as $=\mathrm{SE}(\mathrm{C} 18="$ "";0;C25/C18)

- C30: Quantity of vehicles produced by section, given by $=\mathrm{C} 17$

- C31: Vehicular load factor per section, which results as $=\mathrm{SE}(\mathrm{C} 18="$ ";0;C17/C18); given by the ratio Qbep/CP, it is the factor of the exploitation of available capacity and it is a way to express the BEP in relation to production capacity

- C32: Degree of Operating Leverage/Economic risk, given by $=(\mathrm{C} 20-\mathrm{C} 21) /(\mathrm{C} 20-\mathrm{C} 21+\mathrm{C} 22)$

- C33: Balance of Production Capacities, given by $=(\mathrm{C} 20-(\mathrm{C} 22+\mathrm{C} 21)) / \mathrm{C} 20$

- C34: Revenue per section, given by the field $=\mathrm{C} 20$

- C35: Average variable costs per unit, given by = C21

- C36: Gross margin of the average contribution per unit, given by $=\mathrm{C} 34-\mathrm{C} 35$

- $\quad$ C37: Average unitary fixed costs, given by $=\mathrm{C} 22$ 
- $\quad$ C38: Operating revenue, given by $=\mathrm{C} 36-\mathrm{C} 37$

- C40: Percentage variation of the operating revenue

- C41: Percentage variation in the expected revenues

- C42: Operating Revenue Expected, given by $=\mathrm{C} 38 * \mathrm{C} 40+\mathrm{C} 38$

- $\quad \mathrm{C} 43$ : Expected revenue, given by $=\mathrm{C} 41 * \mathrm{C} 34+\mathrm{C} 34$

- $\quad$ C44: Percentage operating leverage $=\mathrm{C} 43 / \mathrm{C} 42$. The operating leverage is an index that measures the effect of changes in the volume of revenues from tariffs on Operating Revenue RO

- C46: Operating Revenue to achieve (for a range of sensitivity increased by $20 \%$ )

- C47: Quantity to produce, given by $=\mathrm{SE}(\mathrm{O}(\mathrm{C} 7=" "$;C8="'");0;(C46+C22)/(C36))

- $\mathrm{C} 48$ : Degree of the utilization of the productive capacity, given by $=\mathrm{SE}(\mathrm{C} 18="$ "';0;C47/C18)

The application, with data entered, is represented - not commented - purely by way of simplification annotated in Figure 8, demonstrating the effectiveness of the model designed above and for the stimulation of the reader.

\begin{tabular}{|c|c|c|}
\hline A & B & $\mathrm{C}$ \\
\hline 2 & Description & Class \\
\hline 3 & \multicolumn{2}{|l|}{ Data Entry } \\
\hline 4 & Length of motorway section in meters & 3000 \\
\hline 5 & Average vehicular speed for the roadway lane and for the carriageway $(\mathrm{Km} / \mathrm{h})$ & 130 \\
\hline 6 & Time of observation of the section (seconds) & 3600 \\
\hline 7 & Unitary toll per section per vehicle class $(<\Rightarrow>1.30 \mathrm{mt}$. on front axle) & 0,18 \\
\hline 8 & Annual variable cost per section & 450000 \\
\hline 9 & Annual fixed cost per section & 585390 \\
\hline 10 & Maximum speed per section $(\mathrm{km} / \mathrm{h}$ or $130 \mathrm{~km} / \mathrm{h} 150)$ & 130 \\
\hline \multicolumn{3}{|c|}{ (1) } \\
\hline 12 & \multicolumn{2}{|l|}{ Break-Even analysis* } \\
\hline 13 & \multicolumn{2}{|c|}{$\begin{array}{l}\text { * parameters according to the legislative decree n. } 285 \text { of } 30 \text { April } 1992 \text { and to the conversion law no. } 214 \text { of } 1 \text { August } 2003 \text { (published in } \\
\text { Official Gazette no. } 186 \text { of } 12 \text { August } 2003-\text { SO n. 133) }\end{array}$} \\
\hline 14 & Description & Class \\
\hline 15 & Crossing time of the section (seconds) & $=\mathrm{C} 4 / 1000 / \mathrm{C} 5 * 3600$ \\
\hline 16 & Maximum quantity of observable vehicles per roadway lane and carriageway & $=\mathrm{C} 6 / \mathrm{C} 15 * \mathrm{C} 17$ \\
\hline 17 & Vehicles per section (quantity) & $\begin{array}{l}=\text { CERCA.VERT('Figure } 6 \text { '!C5;'Figure } \\
1 \text { '!\$A2:\$F21;2;VERO) }\end{array}$ \\
\hline 18 & Maximum vehicles capacity per section & $=\mathrm{SE}(\mathrm{C} 10=130 ;$ 'Figure 1'!F $\$ 14 ; '$ Figure 1'!F\$16) \\
\hline 19 & Vehicular percentage variation of the maximum speed per section & $=-(\mathrm{C} 18-\mathrm{C} 17) / \mathrm{C} 18$ \\
\hline 20 & Toll-per-section per observation time & $=\mathrm{C} 7 * \mathrm{C} 16$ \\
\hline 21 & Variable cost per section per observation time & $=\mathrm{C} 8 / 365 / 24 / 60 / 60 * \mathrm{C} 6$ \\
\hline 22 & Fixed costs per section per observation time & $=\mathrm{C} 9 / 365 / 24 / 60 / 60 * \mathrm{C} 6$ \\
\hline \multicolumn{3}{|c|}{ 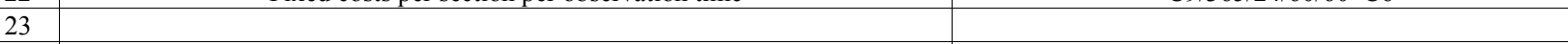 } \\
\hline 24 & Calculation of the equilibrium quantity (Break-Even Point) per section & Class \\
\hline 25 & Equilibrium quantity - Break-Even Point for unitary section & $=\mathrm{SE}\left(\mathrm{O}\left(\mathrm{C} 7="{ }^{\prime} ; \mathrm{C} 8=" ' "\right) ; 0 ; \mathrm{C} 22 /(\mathrm{C} 20-\mathrm{C} 21)\right)$ \\
\hline 26 & Revenue of equilibrium & $=\mathrm{C} 22 /(1-(\mathrm{C} 21 / \mathrm{C} 20))$ \\
\hline 27 & Rate of utilization of the vehicular productive capacity & $=\mathrm{SE}(\mathrm{C} 18=" ' ; 0 ; \mathrm{C} 25 / \mathrm{C} 18)$ \\
\hline \multicolumn{3}{|c|}{ 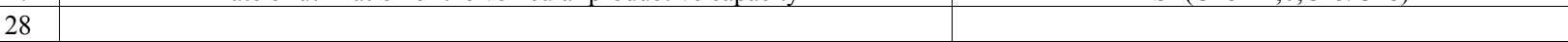 } \\
\hline 29 & Calculation of Operating Result per section & Class \\
\hline 30 & Quantity of vehicles produced per section & $=\mathrm{C} 17$ \\
\hline 31 & Vehicle load factor per section & $=\mathrm{SE}(\mathrm{C} 18=" ' ; 0 ; \mathrm{C} 17 / \mathrm{C} 18)$ \\
\hline 32 & Degree of operating leverage $=$ Economic risk & $=(\mathrm{C} 20-\mathrm{C} 21) /(\mathrm{C} 20-\mathrm{C} 21+\mathrm{C} 22)$ \\
\hline 33 & Balance of Production Capacities & $=(\mathrm{C} 20-(\mathrm{C} 22+\mathrm{C} 21)) / \mathrm{C} 20$ \\
\hline 34 & Revenue per section & $=\mathrm{C} 20$ \\
\hline 35 & Average variable costs per unit & $=\mathrm{C} 21$ \\
\hline 36 & Gross margin of the average unitary contribution & $=\mathrm{C} 34-\mathrm{C} 35$ \\
\hline 37 & Average unitary fixed costs & $=\mathrm{C} 22$ \\
\hline 38 & Operating revenue & $=\mathrm{C} 36-\mathrm{C} 37$ \\
\hline 39 & Operating lever & Class \\
\hline 40 & Percentage variation of operating revenue & 0,01 \\
\hline 41 & Percentage variation of the expected revenue & 0,01 \\
\hline 42 & Operating Revenue Expected & $=\mathrm{C} 38 * \mathrm{C} 40+\mathrm{C} 38$ \\
\hline 43 & Expected Revenue & $=\mathrm{C} 41 * \mathrm{C} 34+\mathrm{C} 34$ \\
\hline 44 & Percentage operating leverage & $=\mathrm{C} 43 / \mathrm{C} 42$ \\
\hline 45 & Calculation of the quantities to be produced by varying the Operating Revenue & Class \\
\hline 46 & Operating revenue to achieve & 145,5 \\
\hline 47 & Quantity to produce & $=\mathrm{SE}(\mathrm{O}(\mathrm{C} 7=" '+\mathrm{C} 8=" ' ") ; 0 ;(\mathrm{C} 46+\mathrm{C} 22) /(\mathrm{C} 36))$ \\
\hline 48 & Degree of the utilization of the productive capacity & $=\mathrm{SE}\left(\mathrm{C} 18="{ }^{\prime} ; 0 ; \mathrm{C} 47 / \mathrm{C} 18\right)$ \\
\hline
\end{tabular}

Figure 7. The algorithms of the table of MPCA account parameters (with "International Auxiliary Language" number notation) 
We submit a brief description of an application to be read according to the synoptic analysis.

\begin{tabular}{|c|c|c|}
\hline A & B & $\mathrm{C}$ \\
\hline 2 & Description & Class \\
\hline 3 & \multicolumn{2}{|c|}{ Data Entry } \\
\hline 4 & Length of motorway section in meters & 3.000 \\
\hline 5 & $\begin{array}{l}\text { Average vehicular speed for the roadway lane and for the carriageway } \\
\qquad(\mathrm{Km} / \mathrm{h})\end{array}$ & 130 \\
\hline 6 & Time of observation of the section (seconds) & 3.600 \\
\hline 7 & Unitary toll per section per vehicle class $(<=>1.30 \mathrm{mt}$. on front axle) & 0,18 \\
\hline 8 & Annual variable cost per section & 450.000 \\
\hline 9 & Annual fixed cost per section & 585.390 \\
\hline 10 & Maximum speed per section $(\mathrm{km} / \mathrm{h}$ or $130 \mathrm{~km} / \mathrm{h} 150)$ & 130 \\
\hline \multicolumn{3}{|l|}{11} \\
\hline 12 & \multicolumn{2}{|c|}{ Break-even analysis* } \\
\hline 13 & \multicolumn{2}{|c|}{$\begin{array}{l}\text { * parameters according to the legislative decree n. } 285 \text { of } 30 \text { April } 1992 \text { and to the conversion law no. } 214 \text { of } 1 \text { August } 2003 \text { (published in } \\
\text { Official Gazette no. } 186 \text { of } 12 \text { August } 2003-\mathrm{SO} \text { n. 133) }\end{array}$} \\
\hline 14 & Description & Class \\
\hline 15 & Crossing time of the section (seconds) & 83 \\
\hline 16 & $\begin{array}{l}\begin{array}{l}\text { Maximum quantity of observable vehicles per roadway lane and } \\
\text { carriageway }\end{array} \\
\text {. }\end{array}$ & 1.095 \\
\hline 17 & Vehicles per section (quantity) & 25 \\
\hline 18 & Maximum vehicle capacity per section & 31 \\
\hline 19 & Vehicular percentage variation of the maximum speed per section & $-17,66 \%$ \\
\hline 20 & Toll-per-section per osservation time & 197,17 \\
\hline 21 & Variable cost per section per observation time & 51,37 \\
\hline 22 & Fixed costs per section per observation time & 66,83 \\
\hline \multicolumn{3}{|l|}{23} \\
\hline 24 & Calculation of the equilibrium quantity (Break-Even Point) per section & Class \\
\hline 25 & Equilibrium quantity - Break-Even Point for unitary section & 0,46 \\
\hline 26 & Revenue of equilibrium & 90,37 \\
\hline 27 & Rate of utilization of the vehicle productive capacity & $1,49 \%$ \\
\hline \multicolumn{3}{|l|}{28} \\
\hline 29 & Calculation of Operating Result per section & Class \\
\hline 30 & Quantity of vehicles produced per section & 25 \\
\hline 31 & Vehicle Load factor per section & $82 \%$ \\
\hline 32 & Degree of operating leverage $=$ Economic risk & $68,57 \%$ \\
\hline 33 & Balance of Production Capacities & $40,05 \%$ \\
\hline 34 & Revenue per section & 197,17 \\
\hline 35 & Average variable costs per unit & 51,37 \\
\hline 36 & Gross margin of the unitary average contribution & 145,80 \\
\hline 37 & Average unitary fixed costs & 66,83 \\
\hline 38 & Operating revenue & 78,97 \\
\hline 39 & Operating Lever & Class \\
\hline 40 & Percentage variation in operating revenue & $1,00 \%$ \\
\hline 41 & Percentage variation in expected revenue & $1,00 \%$ \\
\hline 42 & Operating Revenue Expected & 79,76 \\
\hline 43 & Expected Revenue & 199,14 \\
\hline 44 & Percentage operating leverage & $249,67 \%$ \\
\hline 45 & $\begin{array}{l}\text { Calculation of the quantities to be produced for varying the Operating } \\
\text { revenue }\end{array}$ & Class \\
\hline 46 & Operating revenue to achieve & 145,50 \\
\hline 47 & Quantity to produce & $145,63 \%$ \\
\hline 48 & Degree of the utilization of the productive capacity & $4,74 \%$ \\
\hline
\end{tabular}

Figure 8. The algorithms of the table of MPCA account parameters (with "International Auxiliary Language" number notation). Application 


\section{Conclusions}

There are still some questions to be answered, searching for the best economic account set.

First of all, safety and revenues from traffic speed are correlated variables in theoretical conditions: safety decreases with increasing speed limits, whereas revenues decrease with increasing average speed.

In this case, in fact, increasing speed does induce a reduction of traffic density; traffic density reduction means less number of vehicles per (motorway) section and, thus, fewer revenues.

Particularly, the latter assumption is not questionable in legal constrain conditions.

Some scholars might argue that it would be more appropriate to link revenues to traffic flows (rather than density): increasing traffic flows mean more vehicles in time and therefore more revenues. In such a way, congestion might be properly taken into account, provided that typically two different traffic volumes can be observed for the same level of average traffic speed in a section (e.g. free-flow regime and congestion).

Against any possible objection by scholars we oppose:

- The effect of framing: substantially identical data, that are placed in different conceptual structures, produce different decision outcomes.

- In the case of land transport stream lines, vehicular fluxes to which reference is made have approximately the same potential energy.

- "Only in free traffic flow (and not in legal conditions), empirical data show a positive correlation between the flow rate (in vehicles per unit time) and vehicle density (in vehicles per unit distance). This relationship stops at the maximum free flow with a corresponding critical density.

- Only when the number of vehicles on a road, e.g. the density, becomes too high, the state of the traffic is metastable. This means that only when small uncertain perturbations occur, the state is still stable; however, when larger perturbations occur, the traffic is unstable and moving jams will emerge. Only during a synchronized flow ${ }^{13}$, the downstream front - where the vehicles accelerate to free flow - does not show this characteristic feature of the wide moving jam. In addition, there is a tendency towards synchronization of vehicle speeds in each of the road lanes (bunching of vehicles) in synchronized flow" ${ }^{14}$. Moreover, in three-phase traffic theory (e.g. Treiber M., Kesting A., Helbing D. [32]) the set of the fundamental empirical features of traffic breakdown is explained by the $\mathrm{F} \rightarrow$ $\mathrm{S}$ transition. Probably, the most important

13 The term synchronized flow is meant to reflect the following features of this traffic phase: (i) It is a continuous traffic flow with no significant stoppage, as often occurs inside a wide moving jam. (ii) There is a tendency towards synchronization of vehicle speeds across different lanes on a multilane road in this flow.

14 (From: https://en.wikipedia.org/wiki/Three-phase_traffic_theory). consequence of that is the existence of a range of highway capacities between some maximum and minimum capacities (in this regard Kerner explains the nature of the $\mathrm{F} \rightarrow \mathrm{S}$ phase transitions by a competition of "speed adaptation" [33]).

Then, since it is not possible directly to affect human behavior in conducting the vehicles on the roadway lane section and on the carriageway, without real interventions into illegality areas, it is useful to know which real intervention are possible in order to make planning.

The demonstrated way shows that the human decision-making action of the external - under uncertainty/certainty factors - has much impact.

Instead, the use of classic mobility modeling for the prevention of critical phenomena is less useful.

If anything, the modeling appears to be a useful tool especially for project planning and programming of general management.

Finally, the reflections in response to what it's called in the title of the article, require the adoption of robust instruments of knowledge of critical phenomena.

In this case, in conditions of uncertainty/certainty, the treatment by the IT interactive model MPCA is - quantifying at the same time for traffic, both the density and flows - a robust method for the determination of revenues from traffic under crisis conditions.

\section{REFERENCES}

[1] Kroes E.P., Sheldon R.J. (1988). "Stated preference methods, an introduction", Journal of Transport Economics and Policy, 22 (1) 11-25 May A. (1990), Traffic Flow Fundamentals, Prentice Hall, N.Y.

[2] Zhou M., Sisiopiku V.P., 1997. "Relationship between volume-to-capacity ratios and crash rates", Transportation Research Board, Record 1581, 47-52.

[3] Ferrari P. (1988). Un modello di simulazione per l'analisi del comportamento dei conducenti in autostrada, Atti del convegno AIRO, Pisa, Italy.

[4] Garavello M., Piccoli B. (2006). Traffic flow on network, Applied Math Series, vol. 1, American Institute of Mathematical Sciences, 12, 15, 16, 17, 20, 59.

[5] Camus R., Longo G., Santorini F. (1995). "La distribuzione delle velocità nel flusso autostradale, elemento indicatore del differente comportamento dell'utenza nei modelli di previsione a breve termine", IV Congresso nazionale SIDT, Torino, Italy.

[6] Schultz G.G., Rilett L.R. (2004). "Analysis of Distribution and Calibration of Car-Following Sensitivity Parameters", in: Microscopic Traffic Simulation Models, 11.

[7] Toledo T., Koutsopoulos H.N., Davol A., Ben-Akiva M.E., Burghout W., Andréasson I., Johansson T., C. Lundin (2003). "Calibration and Validation of Microscopic Traffic Simulation Tools, Stockholm Case Study", Proceedings of 
the $82^{\text {rd }}$ annual meeting TRB, Washington, D. C.

[8] Ranjitkar P., Nakatsuji T. (2010). A trajectory based analysis of driver's response in car following situations, TRB 2010 Annual Meeting CD-ROM, 21.

[9] Schultz G.G., Rilett L.R. (2004). "Analysis of Distribution and Calibration of Car-Following Sensitivity Parameters", in: Microscopic Traffic Simulation Models, 11.

[10] Ferrari P. (1989). The effect of driver behavior on motorway reliability, Transportation Research, 23B, 2, 139-150.

[11] Torrieri V., Gattuso D., Vitetta A. (1995). "Density and conditioning characteristics of motorway vehicular traffic flow", Proceeding of AATT Conference, Capri, Italy.

[12] Gis P.G. (1981). A behavioral car-following model for computer simulation, Transportation Research-B, 15, 105-111.

[13] Siuhi S., Kaseko M. (2010). "Parametric study of stimulus-response behavior for car-following models", TRB 2010 Annual Meeting CD-ROM.

[14] Duderstadt James J., Martin William R. (1979). Transport theory, cap. 4, "The derivation of continuum description from transport equations", New York, Wiley-Interscience Publications.

[15] Quartapelle L., Auteri, F. (2013). Fluidodinamica incomprimibile, Casa Editrice Ambrosiana, Rozzano-Milano, Italy.

[16] Kühne R., Michalopoulos P. (1992). "Continuum Flow Models" in: Traffic Flow Theory - a State-of-the-Art-Report, Transportation Research Board.

[17] Kundu P.K., Cohen I.M. (2004). Fluid Mechanics, Third Edition, Elsevier Academic Press.

[18] Musolino G., Vitetta A. (1995). "Il condizionamento dei veicoli in autostrada", Atti del $2^{\circ}$ seminario "Rilievi e modellizzazione del traffico veicolare", Dipartimento di Ingegneria dei Trasporti, Università degli Studi di Napoli, Napoli, Italy.

[19] Anas A. (1981). "The estimation of multinomial logit models of joint location and travel mode choice from aggregate data", Journal of Regional Science, $\mathrm{n}^{\circ} 21$, 223-242.

[20] De Levie Robert (2004). "Algorithmic accuracy", Advanced Excel for scientific data analysis, Oxford University Press. 44.

[21] Walkenbach J. (2010), "Defining data types", Excel 2010 Power Programming with VBA, Wiley, $198 \mathrm{ff}$ and Table 8-1.

[22] Jensen C., Anderson L. (1992). Harvard graphics 3: the complete reference. Osborne McGraw-Hill ISBN $0-07-881749-8, .413$.
[23] Van Orman Quine W. (1976). The Ways of Paradox. Harvard Univ. Press.

[24] Menneni S., Sun C.P.D., Vortisch P. (2008). An Integrated Microscopic and Macroscopic Calibration for Psycho-Physical Car Following Models, TRB 2009 Annual Meeting CD-ROM, 17.

[25] Wald A. (1945). "Statistical decision functions which minimize the maximum risk", The Annals of Mathematics, 46(2), 265-280.

[26] Jaffray J.Y., Jeleva M., (16-19 July 2007). "Information Processing under Imprecise Risk with the Hurwicz criterion", International Symposium on Imprecise Probability: Theories and Applications (conference proceedings via sipta.org), Retrieved 2007-10-19.

[27] Oxley, J.G. (2006). "Example 1.2.7", Matroid Theory, Oxford Graduate Texts in Mathematics 3, Oxford University Press, 19- 26.

[28] Arcaini P., Cordone R. http: //homes.di.unimi.it / cordone/courses/2009-mmsd/Lez15-090430-PCI.pdf.

[29] Averbakh I., Lebedev V. (2004). Interval data minmax regret network optimization problems, Discrete Applied Mathematics, $n^{\circ} 138,289-301$.

[30] Ferrarese M. (2015). A Spatial-temporal Epistemology of Four-dimension Transportation Issue, Universal Journal of Applied Science, HRPC, 3(1): 6 - 12.

[31] Karasan O.E., Pinar M.C., Yaman H. (2001). The robust shortest path problem with interval data, Bilkent University, Ankara, Turkey.

[32] Treiber M., Kesting A., Helbing D. (2010). "Three-phase traffic theory and two-phase models with a fundamental diagram in the light of empirical stylized facts". Transportation Research Part B: Methodological 44, 983-1000.

[33] Kerner B.S. (1999). "Congested Traffic Flow: Observations and Theory", Transportation Research Record, Vol. 1678, 160-167.

\section{Webography}

$\checkmark$ https://en.wikipedia.org/wiki/International_auxiliary_langua ge

\footnotetext{
$\checkmark \quad$ http://disi.unitn.it/ montreso/asd/lucidi/14-greedy-up.pdf

http:

//homes.di.unimi.it/ cordone/courses/2009-mmsd/Lez15-09 0430-PCI.pdf

https://mathway.com/

http://sipta.org

$\checkmark \quad$ https://en.wikipedia.org/wiki/Three-phase_traffic_theory
} 